\title{
SERVICE SYSTEM INNOVATION
}

\author{
Steven Alter \\ University of San Francisco \\ San Francisco, CA U.S.A.
}

\begin{abstract}
Service innovation has been discussed by many authors, but usually not from a system perspective. Recent literature about service systems and service innovation stresses multi-partner commercial offerings, ecosystems of interacting suppliers and consumers, globalization, and the changing nature of advanced economies. Interesting as these large-scale topics are, discussions at that level tend to overlook operational and organizational issues that service innovators must address in order to create or improve specific, localized systems that deliver services to internal and/or external customers.

This paper builds on three interrelated frameworks that describe fundamental aspects of service systems at the level at which they are designed, operated, and improved:
\end{abstract}

- The work system framework identifies nine elements that should be included in even a rudimentary understanding of any work system. (Service systems are work systems.)

- The service value chain framework incorporates characteristics often associated with services, such as coproduction by providers and customers.

- $\quad$ The work system life cycle model treats the system's life cycle as a set of iterations involving planned and unplanned change.

This paper shows how each of those three frameworks provides insights that apply to service innovation across a wide range of service systems.

Keywords Service innovation, service system, definition of service, work system framework, service value chain framework, work system life cycle model

Please use the following format when citing this chapter:

Alter, S., 2008, in IFIP International Federation for Information Processing, Volume 267, Information Technology in the Service Economy: Challenges and Possibilities for the $21^{\text {st }}$ Century, eds. Barrett, M., Davidson, E., Middleton, C., and DeGross, J. (Boston: Springer), pp. 61-80. 


\section{INTRODUCTION}

Over half of the revenues of technology companies come from services (Wood 2007). Noting the increasing importance of services in the economy in general and for technology companies in particular, IBM joined with other technology companies in a major initiative to develop university courses of study related to service and to develop "service science" (Chesbrough and Spohrer 2006; Spohrer et al. 2007). Motivations for this initiative included the long term need to hire employees who can succeed in a service economy and the belief that many practical and theoretical ideas related to service are not yet well developed.

This paper presents a broadly useful view of service system innovation (SSI). Service innovation is mentioned often in discussions of service, and many examples of service innovation have been described. However, service innovation is rarely presented as a type of business initiative that can be analyzed and implemented based on an organized set of ideas that apply to almost all services, not just hospitality or retail or e-commerce or e-government. Similarly, the term service system appears frequently but is rarely defined clearly or used as an analytical concept.

The term service system innovation is especially rare in the service innovation literature, which contains many discussions of service innovation, service systems, and service system engineering. For example, a Google search on "service system innovation" on March 9, 2008, returned only 66 hits, many of which were tangentially relevant or irrelevant. Many the relevant hits involved Methodology for Product Service System Innovation: How to Implement Clean, Clever, and Competitive Strategies in European Industries (van Halen et al. 2005). While that book certainly deals with system-related issues, it focuses on strategic issues and partnerships between firms. For example, it says "product service systems theory brings companies to a new strategic level and provides new industrial perspectives. It opens new approaches on value creation, social context and industrialization visions" (p. 18). In contrast, our discussion of service system innovation applies to both internally and externally directed services.

The goal in this paper is to provide a system-oriented view of service innovation that is based on service system concepts and is both useful and broadly applicable. Going beyond defining service innovation or providing accounts of service innovation in particular settings, this paper couches service innovation in terms of an organized set of ideas about service system innovation that should help in describing, analyzing, and researching how service systems are created, how they operate, and how they evolve over time through a combination of planned and unplanned change.

This paper proceeds as follows. After reviewing existing definitions of service, it defines service, service system, and service innovation. It explains that the proposed definitions differ from corresponding definitions reflecting very recent thought in the service science community. It presents three frameworks related to systems and services and shows how each framework provides an analytical lens and a set of insights that managers and service innovators can use for describing, analyzing, and implementing specific service system innovations. Each framework has been discussed in considerably more depth, and would yield many additional implications in a longer paper or book. The main contribution of this paper is its demonstration of basic implications of viewing service innovation from a service system innovation (SSI) perspective organized around the three frameworks. 


\section{Basic Definitions}

There is surprisingly little agreement about definitions of service and service innovation. Debates about the definition of service stem from difficulties distinguishing between goods (often called products) and services. Most marketing books bypass this issue by saying that offerings to customers often combine product and service features.

Existing definitions of service. Researchers in marketing, operations, and computer science discuss and analyze services from vastly different viewpoints. Table 1 lists a number of definitions, four of which were cited by Rai and Sambamurthy (2006), who said,

there is reasonable triangulation on what services are...in general, the definitions emphasize a simultaneous or near-simultaneous exchange of production and consumption, transformation in the experience and value that customers receive from engagement with providers, and intangibility in that goods are not exchanged (p. 328).

Rai and Sambamurthy's "reasonable triangulation" is open to question because many service situations fit neither their triangulation nor the definitions in Table 1. Many views of service emphasize the customer's subjective experience of person-to-person service encounters, for example, Carlzon's (1989) term "moments of truth" and Teboul's (2006) book, Service Is Front Stage. Subjective experience of service encounters is less important (although still present) for highly automated services (e.g., web-based mortgage brokers or semi-automated translation services), back office services (producing tax returns or generating market research reports), computer-to-computer services (e.g., remote monitoring of equipment or automatic backups), and self-service situations (e.g.,

\section{Table 1. Typical Definitions of Service}

"A service is a change in the condition of a person, or a good belonging to some economic
entity, brought about as a result of some other economic entity, with the approval of the first
person or economic entity" (Hill 1977, p. 318).
"A service is any act or performance that one party can offer to another that is essentially
intangible and does not result in the ownership of anything" (Kotler and Keller 2006, p. 402).
"A service is a time-perishable, intangible experience performed for a customer acting in the
role of a coproducer" (Fitzsimmons and Fitzsimmons 2006, p. 4).
Services are "the application of specialized competencies (knowledge and skills) through
deeds, processes, and performances for the benefit of another entity of the entity itself" (Vargo
and Lusch 2004, p. 2).

Service is "the application of competences (knowledge skills, and resources) for the benefit of another entity in a mutually agreed and mutually beneficial manner" (IfM and IBM 2007, p. 16).

"Service [is] the application of resources for the benefit of another" (Vargo and Lusch cited in Spohrer et al. 2008, p. 1).

An article called "Foundations and Implications of a Proposed Unified Services Theory" found one unique characteristic that differentiates services from products: "with service processes, the customer provides significant inputs into the production process" (Sampson and Froehle 2006, p. 331). 
using an ATM). Subjective experiences are of no importance in computer scientists' views of services, such as "a service is generally implemented as a course-grained, discoverable software entity that exists as a single instance and interacts with applications and other services through a loosely coupled (often asynchronous), message-based communication model" (Brown et al. 2005, p. 728).

Definition of service. We adopt a simple, dictionary-like definition by which the following are all services: performing surgery, installing networks, producing customized software, providing Internet-based search capabilities, accepting orders through an e-commerce web site, building houses, producing televisions, providing leisure opportunities on golf courses, performing legal work, and selling groceries.

Services are acts performed for others, including the provision of resources that others will use.

This definition applies to a wide range of services:

- $\quad$ services for external customers and for internal customers

- $\quad$ automated, IT-reliant, and nonautomated services

- customized, semi-customized, and non-customized services

- $\quad$ personal and impersonal services

- $\quad$ repetitive and non-repetitive services

- long-term and short-term services

- $\quad$ services with varying degrees of self-service responsibilities

It applies to the three types of value configurations discussed by Stabell and Fjeldstad (1998): value chains, value networks, and value shops. It covers special cases such as self-service and automated services for people. In self-service, service providers provide resources that are used by customers performing self-service activities. In automated services for people, machines perform the service activities.

This definition is similar to the Vargo and Lusch definitions in Table 1, but differs from other definitions in a number of ways. Contrary some of the definitions in Table 1 and to Rai and Sambamurthy's triangulated definition (mentioned above), it says nothing about service characteristics such as intangibility, customization, simultaneity of production and consumption, time-perishability, or involvement of customer interactions or experiences. Such characteristics are treated as continuous design variables that apply to different services in differing degrees and can be set to different levels depending on the goals of the service situation. Similarly, while coproduction of value is often associated with services, coproduction can also be viewed as a continuous design variable whose different levels include

- The customer provides a request for service (minimal level of coproduction).

- Customers participate in some aspects of service fulfillment processes (beyond specifying requirements).

- The service occurs largely through service interactions including direct participation by customers.

- A self-service approach is used, whereby the service provider creates and provides the means by which the customer performs self-service processes and activities. 
Two other aspects of the definition are worth mentioning. The definition says nothing about provider-customer interactions because many services involve minimal customer interaction. In self-service, for example, provider-customer interaction devolves to the customer's use of the provider's technical artifacts and procedures. The fact that such usage might be viewed as an interaction, especially from the viewpoint of actor-network theory, is not sufficient to include interaction as part of the definition. In addition, the definition does not assume services are provided "in a mutually agreed and mutually beneficial manner," a phrase included in a definition in Table 1 that appeared in a recent discussion paper produced by an international symposium of service research leaders and others committed to developing service science (IfM and IBM 2007). That phrase is normatively attractive but inconsistent with practice, as noted in a recent Harvard Business Review article (McGovern and Moon 2007) that discusses how companies in cell phone service, airlines, banking, health clubs, car rental, and credit cards take advantage of customers through increasingly opaque, provider-centric strategies that are not designed for customer benefit.

Probably the most controversial aspect of our dictionary-like definition is that it ignores the traditional distinction between goods and services because a precise boundary is of little practical importance in marketing, operations, or information systems. The "service-dominant logic" (contrasted with "goods-dominant logic") proposed by Vargo and Lusch (2004) addresses the goods versus service issue by proposing that "goods are distribution mechanisms for service provision" (p. 8). This idea mirrors Levitt's observation that people who buy quarter-inch drills actually want quarter-inch holes (Christensen et al. 2005, p. 76), whereby the extent to which customer value is delivered is more important than whether it is delivered through goods or services. Instead of pondering the precise dividing line between product and service (e.g., the point where a restaurant meal or a new home flips from product to service), we assume that purposeful activity performed for someone else is a service.

Finally, unlike most other definitions, the definition of service needs only a slight revision to cover service computing (the computer science view). In that realm, which this paper otherwise ignores, another entity replaces others and the definition becomes

Services are acts performed by one entity for another, including the provision of resources that another entity will use.

Definition of service system. A service system is a work system that produces services. "A work system is a system in which human participants and/or machines perform work using information, technology, and other resources to produce products and services for internal or external customers" (Alter 2003, p. 368). Based on the discussion of the definition of service, the distinction between products and services is of little importance when evaluating, analyzing, designing, or implementing systems in realworld situations. If, as mentioned earlier, one views the characteristics commonly ascribed to services as continuous design variables, the important practical issues involve identifying the level of each design variable that is the best compromise between provider and customer needs and interests.

As with the definition of service, the definition of service system is not obvious. For example, a recent paper by service research leaders defined a service system as 
a dynamic value co-creation configuration of resources, including people, organizations, shared information (language, laws, measures, methods), and technology, all connected internally and externally to other service systems by value propositions....Every service system has a unique identity, and is an instance of a type or class of service systems (e.g., people, businesses, government agencies, etc.). The history of a service system is a sequence of interaction episodes with other service systems, including interaction episodes with itself.... Service systems have a beginning, a history, and an end (Spohrer et al. 2008, p. 5).

Our definition of service system does not assume that service systems are dynamic because many typical service systems (such as payroll systems and mass education systems) exist in essentially the same form over extended periods. Also, it says nothing about interacting through value propositions because many services are not voluntary for customers (e.g. elementary education and driver registration). Most important, it views service systems as work systems. Typically one would not view a person as work system; from the other side, most businesses and government agencies of more than minimal size would not be viewed as service systems. Rather they would be viewed as entities consisting of multiple service systems.

Definition of service innovation. Many, and perhaps most, published discussions of service innovation address broad concerns that are somewhat distant from the realities of local decision making and action related to systems that actually produce services. For example, the call for papers for this IFIP 8.2 Working Conference, "IT and Change in the Service Economy," reflects broad, high-level concerns and does not even contain the word system. It sets the context by mentioning transformations within the service economy, globalization, new business models, and new regulatory, normative, and sociocultural institutions at many levels, including societal, industry, profession, organizational, group, and individual.

Consistent with Schumpeter's (1934) distinction between invention and innovation, we define service innovation as the implementation of new services and/or better ways to produce existing services. Consistent with the discussion of innovation in Wikipedia (2008), service innovation may involve any combination of service system changes:

- changes generating incremental value for customers (small innovations that tend to be less interesting as innovations)

- changes generating substantially greater value for customers (large innovations)

- changes that improve the provider's efficiency, cost, quality, or reliability, whether or not customers observe the improvements directly.

Within that view, service innovation involves creating or improving specific service systems such as a firm's systems of hiring employees, finding sales prospects, delivering products and services, performing corporate planning, or providing customer services. It also applies to systems that cross organizations, such as supply chains.

Our definition of service innovation is related to a particular situation and says nothing about whether others may have created similar innovations elsewhere and whether innovation is linked to competition, competitiveness, or globalization. With this situated view, service innovation is fundamentally about creating beneficial improve- 
ments and is not about demonstrating that the resulting service system differs from or is better than other service systems elsewhere. (Nonetheless, competitively significant innovations are often among the most interesting.)

In contrast, the glossary of the service symposium discussion paper mentioned above (IfM and IBM, 2007) defines service innovation as "the combination of technology innovation, business model innovation, socio-organizational innovation, and demand innovation to improve existing or create new service value propositions (offerings or experiences) and service systems." Our definition does not assume that technology innovation, business model innovation, socio-organizational innovation, and demand innovation are all necessarily involved in service innovation. To the contrary, a service innovation may involve little more than installing newer technology or terminating service for customers who absorb excessive resources. Since service innovations might involve internal processes that are invisible to a service system's customers, our definition does not assume that value propositions will necessarily change.

\section{APPLYING THREE FRAMEWORKS}

Our definitions of service, service system, and service innovation form the basis of a system-oriented view of service innovation. Our view of service system innovation (SSI) stems from these definitions, which conform to three interrelated frameworks that describe service systems from a business viewpoint (Alter 2008).

Each framework serves as an analytical lens and provides a set of insights that are useful for describing, analyzing, and implementing specific service system innovations. In contrast to typical analysis and design concepts related to data, workflows, and technology, these frameworks provide concepts that reflect the semantics and business context of services, rather than just computing or engineering concepts. These frameworks can be used to organize many additional concepts related to each element of the frameworks.

Taken together, the three frameworks provide a rich and broadly applicable model of how services operate and evolve. They create a platform for comparing service situations, identifying important special cases of services, and describing service design strategies. In turn, these ideas can contribute to research about relative advantages and disadvantages of different types of innovations in the presence of specific situational characteristics.

\section{THE WORK SYSTEM FRAMEWORK}

The work system framework (Figure 1) uses nine basic elements to provide a system-oriented view of any system that performs work within or across organizations. This framework is the basis of the work system method, a systems analysis method that incorporates many additional concepts related to the individual elements and work systems as a whole. Basic ideas for describing and analyzing work systems are applicable to service systems because service systems are work systems that produce services.

As an illustrative example of a service system, Table 2 shows a work system snapshot related to a hypothetical loan application and underwriting system that combines 


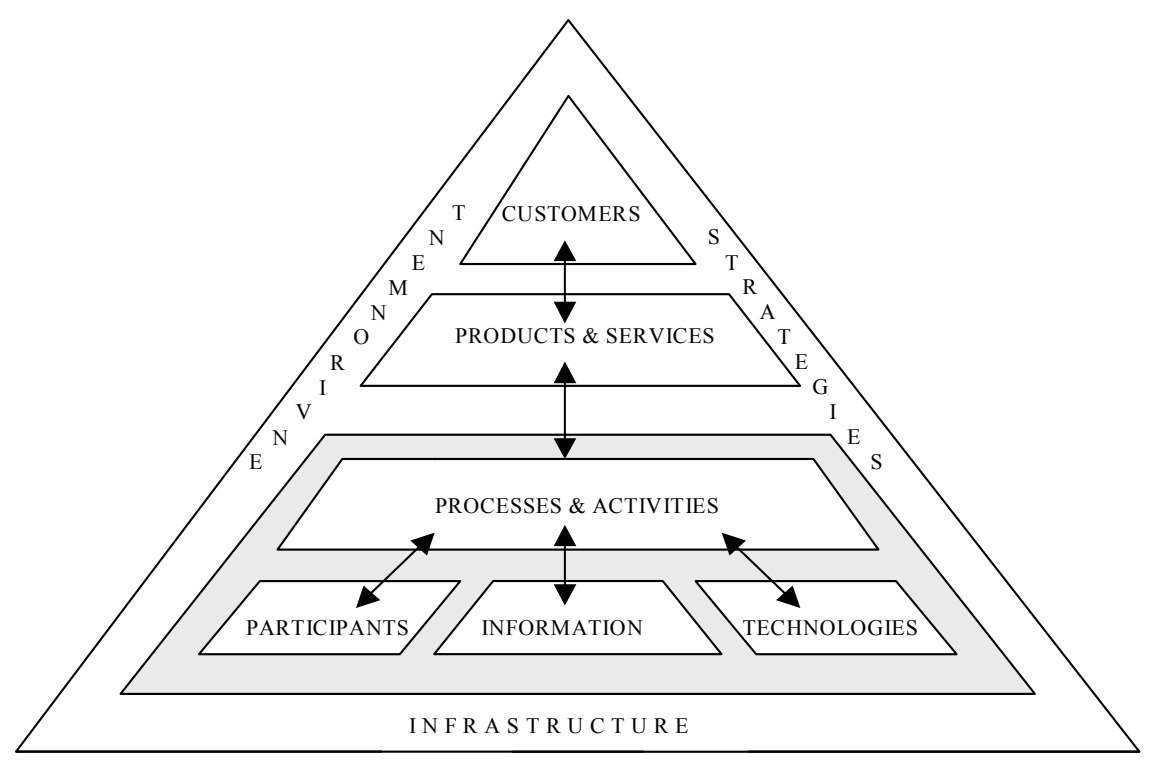

Figure 1. The Work System Framework (slightly updated; Alter 2006, 2008)

functional characteristics from a number of different real-world systems. A work system snapshot is a tabular, one-page summary of a work system based on the six central elements in the work system framework. A service innovator wishing to improve this work system might consider changing any or all of the six elements (and possibly the other three that are not included in the one page summary).

The work system framework illuminates service innovation at two levels, by providing a holistic view of SSI and by providing SSI-related insights about specific work system elements.

At the holistic level, the framework implies that service innovation necessarily involves SSI and is not just about changing whatever customers see. The framework's linkage between specific elements implies that SSI typically involves mutually aligned changes in multiple elements of a service system.

The many facets of SSI (as shown through the work system framework) imply that attempts to design and implement SSI around a single goal for a single performance indicator (e.g., amount of service produced per person-hour of work) are usually shortsighted. On the one hand, potential SSIs should be evaluated based on improvements in efficiency, consistency, employee satisfaction, and other internally directed metrics. On the other hand, for both internal and external customers, performance from the customer perspective is related to total cost borne by the customer (including time and energy expended) and to customer perceptions of quality, responsiveness, reliability, the overall customer experience, and conformance with standards and expectations.

Attributes of the various work system elements form the basis of SSI design decisions at a big-picture level. For example, big-picture SSI decisions related to processes and activities involve issues such as the degree of structure, complexity, and rhythm of 
Table 2. Work System Snapshot for a Loan Application and Underwriting System for Loans to New Clients (Alter 2006)

\begin{tabular}{|l|l|}
\hline \multicolumn{1}{|c|}{ Customers } & \multicolumn{1}{c|}{ Products and Services } \\
\hline - Loan applicant & - Loan application \\
- Loan officer & - Loan write-up \\
- Bank's risk management department and & - Approval or denial of the loan applicaiton \\
top management & - Explanation of the decision \\
(FDIC) (a secondary customer) & - Loan documents \\
\hline \multicolumn{2}{|c|}{ Work Practices (Major Activites or Processes) } \\
\hline
\end{tabular}

- Loan officer identifies businesses that might need a commercial loan.

- Loan officer and client discuss the client's financing needs and discuss the possible terms of the proposed loan.

- Loan officer helps client complete a loan application including financial history and projections.

- Loan officer and senior credit officer meet to verify that the loan application has no glaring flaws.

- Credit analyst prepares a "loan write-up" summarizing the applicant's financial history, providing projections explaining sources of funds for loan payments, and discussing market conditions and applicant's reputation. Each loan is ranked for riskiness based on history and projections. Real estate loans all require an appraisal by a licensed appraiser. (This task is outsourced to an appraisal company.)

- Loan officer presents the loan write-up to a senior credit officer or loan committee.

- Senior credit officers approve or deny loans of less than $\$ 400,000$; a loan committee or executive loan committee approves larger loans.

- Loan officers may appeal a loan denial or an approval with extremely stringent loan covenants. Depending on the size of the loan, the appeal may go to a committee of senior credit officers, or to a loan committee other than the one that made the original decision.

- Loan officer informs loan applicant of the decision.

- Loan administration clerk produces loan documents for an approved loan that the client accepts.

\begin{tabular}{|c|c|c|}
\hline Participants & Information & Technologies \\
\hline $\begin{array}{l}\text { - Loan officer } \\
\text { - } \text { Loan applicant } \\
\text { - } \text { Credit analyst } \\
\text { - } \text { Senior credit officer } \\
\text { - } \text { exan committee and } \\
\text { - Loan administration clerk } \\
\text { - } \text { Real estate appraiser }\end{array}$ & $\begin{array}{l}\text { - Applicant's financial } \\
\text { statements for last three } \\
\text { years } \\
\text { - Applicant's financial and } \\
\text { market projections } \\
\text { - Loan application } \\
\text { - Loan write-up } \\
\text { - Explanation of decision } \\
\text { - Loan documents }\end{array}$ & $\begin{array}{l}\text { - Spreadsheet for consoli- } \\
\text { dating information } \\
\text { - Loan evaluation model } \\
\text { - MS Word template } \\
\text { - Internet } \\
\text { - Telephones }\end{array}$ \\
\hline
\end{tabular}

the processes, and the incentives and expected skill level for the participants. In combination, design decisions related to specific elements result in holistic system characteristics such as centralization/decentralization, capacity, leanness, scalability, resilience, agility, and transparency. 
Customers. SSI is equally applicable to externally facing processes and inwardly facing processes and activities that are services, such as processes for hiring and managing employees, planning, organizing, maintaining facilities and equipment, and qualifying sales prospects. In contrast, discussions of services often assume that services necessarily face outward, as in "our sales revenue increased after we introduced new services for our customers."

Speaking of innovations related to "the customer" of a service system is often misleading. A work system approach quickly reveals that many service systems have multiple customers with different needs and concerns. Those customers often include the direct beneficiaries of whatever a service system produces, plus other customers whose interest and involvement is less direct. For example, direct beneficiaries of a service may not be paying customers (e.g., medical service paid by insurance or employee counseling paid by the employer). SSI directed toward one group of customers may have no effect on other customers or may result in better or worse service for other customers.

Products and Services. SSI often involves combinations of products and services because the actions performed for customers might include the creation and transfer of physical things. The innovator's goal is to design or improve a service system to attain the right combination of internal efficiency and customer satisfaction. Thus, classifications related to products versus services are unimportant for SSI even though these classifications are important for analyzing industry structure and macroeconomic trends.

Processes and Activities. SSI-related changes in processes and activities can support a variety of goals simultaneously. For example, innovations may improve the products and services experienced by customers and/or may improve the provider's efficiency, cost, quality, or reliability whether or not customers observe the improvements directly.

SSI design is about more than changing process details that might be captured in flow charts or business rules. The vocabulary for process-related aspects of SSI includes process design characteristics such as degree of structure, degree of integration, complexity, variety of work, degree of automation, rhythm, time pressure, amount of interruption, error-proneness, and formality of exception handling. Each of these bigpicture decisions can be discussed at a management level to identify situation-specific guidelines that will help in making detailed choices that will appear in flow charts or business rules.

SSI often involves automation of information handling and physical processes. For example, IndyMac Bank's SSI in the mortgage industry converted largely manual processes to highly automated processes, partly by permitting web-based self-service (Krogh et al. 2005). In such situations, the arrows in the work system framework point to a series of corresponding changes that must occur in other work system elements.

Also, SSI sometimes needs to deal with the treatment of workarounds and exceptions, another common work system topic. The SSI question is the extent to which processes and activities should be structured, at least in theory, and the extent to which workarounds should be allowed or even encouraged.

Participants. The success of SSI depends on many factors related to participants, including skills, knowledge, incentives, and presence of a service mindset.

SSI often involves changing roles of participants. Increasingly, SSI incorporates self-service, whereby customers perform functions that were previously performed by the producer's employees. SSI through automation (as in the IndyMac case mentioned 
above) often eliminates roles of some system participants (such as certain mortgage brokers). In such cases, SSI usually includes replacing former participant roles by technician roles focused on maintaining the service system's technology and external infrastructure.

Information. SSI often involves using different information or achieving improvements related to information accuracy, accessibility, timeliness, and so on. As indicated by the arrows in the work system framework, however, better information contributes to SSI only if that information is incorporated into the system's processes and activities.

Technologies. Almost all major service systems rely on IT. However, the headline for understanding and analyzing SSI in specific situations involves the entire system of providing service, rather than the parts that happen to use IT in interesting ways.

Environment. A service system's environment includes organizational culture and relevant regulations, policies and procedures, competitive issues, organizational history, and technical developments. Even within the same business function, company, and industry, a successful SSI in one situation may be unsuccessful in another due to differences in the environment surrounding the service system. Consequently, the common claim that specific practices built into commercial software packages are "best practices" is often misleading for SSI.

Infrastructure. SSI initiatives sometimes succeed or fail based on the presence and operation of human, information, and technical infrastructures that the service system shares with other work systems and does not manage or control. Consequently, SSI design and evaluation should not stop at the boundaries of the service system, and should identify expectations related to external infrastructure.

Strategies. SSI sometimes involves changes in a service system's strategy, which includes its value proposition to its customers and its production strategy. Its value proposition summarizes how customer needs will be met, and at what implicit or explicit cost to customers. Its production strategy concerns how the provider organization will execute the steps it is responsible for performing. SSI projects sometimes encounter problems when the strategies designed into the innovation conflict with strategies of the firm or organization.

\section{THE SERVICE VALUE CHAIN FRAMEWORK}

All of the foregoing observations are equally applicable to all work systems, regardless of whether they are considered service systems. The service value chain framework (Figure 2) augments the work system framework by introducing ideas that are associated specifically with services regardless of whether the customers are internal or external. The entire service value chain for a particular service might be viewed and analyzed as a single work system. Alternatively, different subsystems in Figure 2 (such as provider or customer preparation) might be analyzed as separate work systems.

The two-sided structure of the service value chain framework provides the conceptual motivation for a flexible systems analysis tool called a service responsibility table (SRT) that can be used in various forms throughout the analysis and design of a service system. Table 3 presents an SRT for the example in the work system snapshot in Table 2. The first two columns identify activities and responsibilities of service providers and service consumers. The third column identifies problems and opportunities at each 

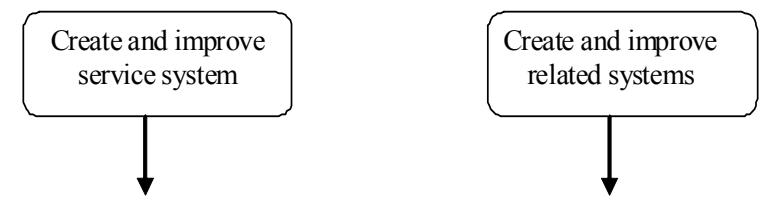

\section{Provider's Responsibilities}

Customer's Responsibilities

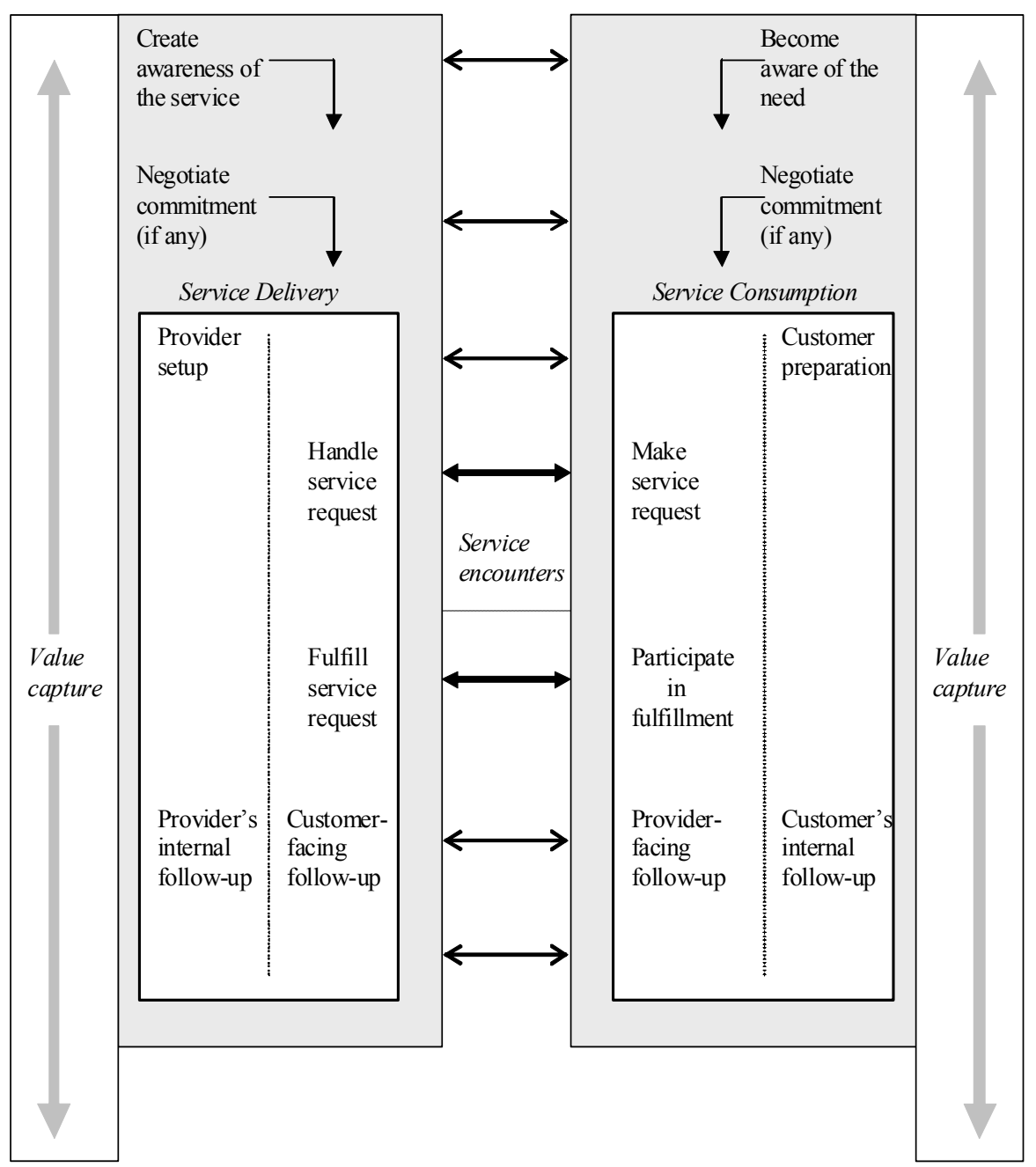

Figure 2. Service Value Chain Framework (updated slightly from Alter 2007, 2008) 
Table 3. Three-Column Service Responsibility Table Including a Column for Problems and Issues (Alter 2007, 2008)

\begin{tabular}{|c|c|c|}
\hline $\begin{array}{l}\text { Provider Activity or } \\
\text { Responsibility }\end{array}$ & $\begin{array}{c}\text { Customer Activity or } \\
\text { Responsibility }\end{array}$ & Problems or Issues \\
\hline $\begin{array}{l}\text { Loan officer identifies } \\
\text { businesses that might need } \\
\text { a commercial loan. }\end{array}$ & & $\begin{array}{l}\text { - Loan officers are not finding } \\
\text { enough leads. }\end{array}$ \\
\hline $\begin{array}{l}\text { Loan officer contacts } \\
\text { potential loan applicant. }\end{array}$ & $\begin{array}{l}\text { Potential loan applicant } \\
\text { agrees to discuss the } \\
\text { possibility of receiving a } \\
\text { loan }\end{array}$ & \\
\hline $\begin{array}{l}\text { Loan officer discusses } \\
\text { loan applicant's financing } \\
\text { needs and possible terms } \\
\text { of the proposed loan. }\end{array}$ & $\begin{array}{l}\text { Potential loan applicant } \\
\text { discusses financing needs. }\end{array}$ & $\begin{array}{l}\text { - Loan officer is not able to be } \\
\text { specific about loan terms, which } \\
\text { are determined during the } \\
\text { approval step, which occurs later. }\end{array}$ \\
\hline $\begin{array}{l}\text { Loan officer helps loan } \\
\text { applicant compile a loan } \\
\text { application }\end{array}$ & $\begin{array}{l}\text { Loan applicant compiles } \\
\text { loan application. }\end{array}$ & $\begin{array}{l}\text { - Loan applicant and loan officer } \\
\text { sometimes exaggerate the appli- } \\
\text { cant's financial strength and } \\
\text { prospects. }\end{array}$ \\
\hline $\begin{array}{l}\text { Loan officer and senior } \\
\text { credit officer meet to } \\
\text { verify that the loan } \\
\text { application has no glaring } \\
\text { flaws. }\end{array}$ & & $\begin{array}{l}\text { - } 20 \% \text { of loans applications have } \\
\text { glaring flaws. }\end{array}$ \\
\hline $\begin{array}{l}\text { Credit analyst prepares a } \\
\text { "loan write-up" summari- } \\
\text { zing the client's financial } \\
\text { history, providing projec- } \\
\text { tions of sources of funds } \\
\text { for loan payments, etc. }\end{array}$ & & $\begin{array}{l}\text { - } 10 \% \text { rate of significant errors, } \\
\text { partly because credit analysts use } \\
\text { an error prone combination of } \\
\text { several spreadsheets and a word } \\
\text { processing program. } \\
\text { - Much rework due to inexperience } \\
\text { of credit analysts. }\end{array}$ \\
\hline $\begin{array}{l}\text { Loan officer presents the } \\
\text { loan write-up to a senior } \\
\text { credit officer or loan } \\
\text { committee. }\end{array}$ & & $\begin{array}{l}\text { - Meetings not scheduled in a } \\
\text { timely manner. } \\
\text { - Questions about exaggerated } \\
\text { statements by some loan officers. }\end{array}$ \\
\hline $\begin{array}{l}\text { Senior credit officer or } \\
\text { loan committee makes } \\
\text { approval decision. }\end{array}$ & & $\begin{array}{l}\text { - Excessive level of nonperforming } \\
\text { loans. } \\
\text { - Rationale for approval or refusal } \\
\text { not recorded for future analysis. }\end{array}$ \\
\hline $\begin{array}{l}\text { Loan officer informs loan } \\
\text { applicant of the decision }\end{array}$ & $\begin{array}{l}\text { Loan applicant accepts } \\
\text { or declines an approved } \\
\text { loan. }\end{array}$ & $\begin{array}{l}\text { - } 25 \% \text { of refused applicants } \\
\text { complain reason is unclear. } \\
\text { - } 30 \% \text { of applicants complain the } \\
\text { process takes too long. }\end{array}$ \\
\hline $\begin{array}{l}\text { Loan administration } \\
\text { clerk produces loan } \\
\text { documents for an approved } \\
\text { loan that the client accepts }\end{array}$ & & \\
\hline
\end{tabular}


step. Alter $(2007,2008)$ identifies many other topics that could be included in SRTs, such as information generated or used, preconditions, important exceptions, typical errors, and even recommendations for improvements related to specific steps.

The service value chain framework is useful in SSI because it identifies both a number of steps and a number of general service topics that could be the focus of service innovations in specific situations. Topics related to the general form of the service value chain framework include coproduction of value, value capture, service interactions, front stage and back stage, and the customer experience. We summarize these topics first, and then look at SSI opportunities in the various steps.

Coproduction of value. The two-sided structure of the service value chain framework is based on the common observation that services are typically coproduced by service providers and customers (Fitzsimmons and Fitzsimmons 2006; Sampson and Froehle 2006; Vargo and Lusch 2004). Accordingly, service design requires attention to activities and responsibilities of both service providers and service customers. (Beyond this paper's scope, Vargo and Lusch suggest that the term coproduction should be replaced by cocreation of value because production brings connotations of manufacturing.)

Value capture. Customers may experience benefits as the service is produced and/or may experience benefits later. Value capture, represented by the left-most and right-most portions of the service value chain framework, includes the customer's experience of attaining value from the service and the provider's experience of attaining value in exchange for the customer's value. Since service systems exist to provide value for customers, SSI efforts should focus substantial attention on augmenting value capture, rather than just improving internal processes or providing a better form of service interactions.

Form and substance of service interactions. The service value chain framework shows that service interactions occur throughout the service value chain, not just when the service is being provided directly. Opportunities for SSI include improving providercustomer interactions during individual steps and creating new ways to integrate activity and information across the various steps.

Assignment of front stage and back stage. Services often involve front stage and back stage activities by both service providers and customers. The front stage versus back stage distinction raises a design challenge about the proper balance between front stage and back stage activities: Which service interactions are necessary, which are desirable, and which processes and activities related to the service are best done back stage? For example, the trend toward self-service is basically about transforming service interactions with the supplier's employees into what the providers might see as back stage activities performed by customers in self-service mode. Providing tools such as web-based self-service affords the provider more visibility of self-service activities.

Customer experience. Although the service fulfillment step in the service value chain model is typically viewed as the core of the service, SSI opportunities may transform or facilitate activities related to any part of the entire experience that typical customers associate with acquiring, receiving, and benefiting from a particular service.

Each of the steps in the service value chain framework affords SSI opportunities.

Prerequisite systems. Systems in organizations are always related to other systems, both for service providers and for their internal and external customers. SSI initiatives should recognize that most service innovations are based on assumptions about comple- 
mentary systems elsewhere. For example, a hospitality system that provides enjoyable resort experiences for vacationers is related to the travel systems that deliver the vacationers to the resort. Travel to the resort may provide SSI opportunities that improve the overall customer experience, such as better ways to deliver vacationers to the resort or providing tourism opportunities on the way.

Awareness. Value creation does not occur if customers are unaware of available services. Consequently, SSI opportunities for a specific service start with better ways to create awareness of the service.

Negotiated commitments. Many service situations involve delivery of services based on negotiated commitments under which the service may be requested and delivered repeatedly. Complex, detailed negotiations related to IT outsourcing represent one extreme of negotiated commitments; simple negotiations leading to verbal agreements about personal services represent the other extreme. Across the entire spectrum of negotiation complexity, SSI can sometimes reduce costs and increase quality of the results for both customers and providers.

Customer and provider preparation. Preparation by providers and/or customers prior to each instance of service delivery is often essential for service efficiency and effectiveness. SSI may improve aspects of the preparation that occur before the service is produced for a specific customer, such as better scheduling and clean-up of examination rooms in a clinic so that patients feel comfortable while waiting for doctors and don't experience excessive waits.

Service request. For many services, each instance of service delivery includes an explicit or implicit service request. This is another area for SSI because handling of the service request is an important part of service delivery and often affects customer satisfaction.

Service fulfillment. Often viewed as the core of services, service fulfillment processes can be improved or facilitated through SSI related to automation of the services, automation of guidelines and control, self-service, enhanced communication and collaboration, and many other approaches.

Follow-up. Some services require follow-up by providers and/or customers. Follow-up may be related to a single service instance (Was the installation OK?) or to multiple service instances (How responsive is your account manager?). In these cases and others, SSI can lead to greater efficiency and effectiveness for providers and customers.

\section{THE WORK SYSTEM LIFE CYCLE MODEL}

The work system life cycle (WSLC) model looks at how work systems (including service systems) change and evolve over time (see Figure 3). It treats a system's life cycle as a set of iterations involving planned and unplanned change. Unlike system development life cycle (SDLC) models that describe programming projects, this framework makes no assumption about whether information technology is involved or whether IT-related changes occur. After creation of the first version of the service system, each iteration of planned change goes through the stages of initiation, development, and implementation, thereby creating the next version of the system. Unplanned change occurs through experimentation and adaptation during any phase of the life cycle. 


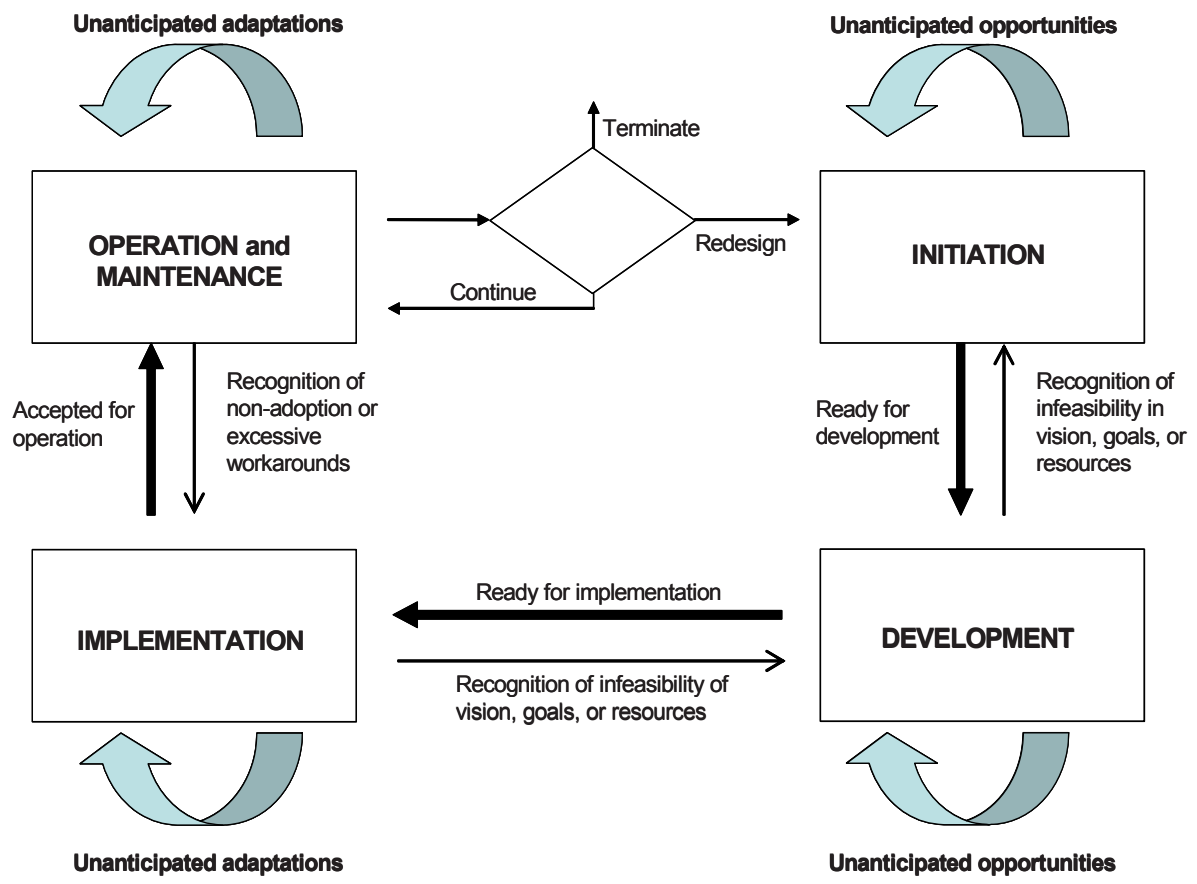

Figure 3. The Work System Life Cycle Model (Alter 2003, 2006, 2008)

The form of the WSLC indicates that SSI is often iterative. Consequently, the innovation strategy for a particular service system might involve frequent incremental changes interspersed with occasional leaps forward. In contrast, note how the SDLC, even in its iterative forms that deliver software in phases, is basically a project model that goes from project initiation to project completion. In other words, the WSLC provides a better long-term picture of how service innovation unfolds as service systems evolve.

SSI opportunities occur during each phase of the work system life cycle model.

SSI during the operation and maintenance phase. SSI during the operation and maintenance of existing systems typically involves unanticipated changes that can be viewed as small innovations. Such changes often involve using software differently or changing procedures. Sometimes they also involve small modifications of software that do not require significant projects.

SSI during the initiation phase. This phase is important for SSI because this is where the direction for planned innovations is negotiated. Discussions during a wellexecuted initiation phase may find that the changes that launched the initiation phase are only part of a larger set of changes that would be required to obtain better results.

SSI during the development phase. The detailed analysis during the development phase often finds additional issues and opportunities that must be dealt with. In some instances, the SSI becomes broader. In others, realization about complexity and capacity limitations during the development phase may result in curtailment of the extent and impact of the innovation. 
SSI during the implementation phase. The implementation phase is another opportunity for SSI that goes beyond the initially intended changes that launched the project. In many cases, participant training and initial usage of software demonstrates that procedures must be changed in unanticipated ways and/or that the software itself must be changed.

A more detailed view of the WSLC (beyond this paper's length restrictions) would reveal many other SSI opportunities. It would also discuss process guidelines, issues related to division of responsibility between business and IT professionals, issues related to change management, and common caveats and pitfalls related to each stage. Suffice it to say that a discussion of SSI tends to be incomplete if it focuses on the service process or outcome and overlooks the service system life cycle.

\section{CONCLUSION: VALUE OF A SERVICE SYSTEM VIEW OF SERVICE INNOVATION}

Business enterprises, government organizations, nonprofits, and departments within larger organizations often need to create service innovations in order to meet their goals, succeed, and even survive. The ideas about SSI presented in this paper could be of substantial use to most organizations because service innovation almost always involves innovation related to the service systems that produce services. Given the importance of service system innovation, rather than service innovation in general, it is perhaps surprising that so little of the marketing, operations, and IS literatures focus on that topic.

We have seen how three interrelated frameworks illuminate important aspects of service system innovation. Individually or in combination, these frameworks can help in describing, analyzing, and researching the nature of service innovations and the processes through which service innovation occurs. A longer paper or a book could have explained those ideas in much greater depth and could have mentioned many other implications for describing and understanding service system innovation.

Moving beyond definitions of service and innovation. This discussion of SSI tried to take a step beyond the ongoing debates about the definitions of service and innovation. It used a simple, dictionary-like definition of service in order to avoid focusing on product versus service distinctions that are of little practical value to managers or IS practitioners, all of whom need to focus on whatever combination of products and services their customers want and need. It also defined innovation in a simple, situated way that reflects management concerns rather than the concerns of economic researchers. These simple, broad definitions facilitated using three frameworks to visualize aspects of service system innovation.

Identifying opportunities for service system innovation. This paper summarized how each of the three frameworks can be used for identifying opportunities for innovation. It identified separate opportunities related to nine elements of the work system framework, five concepts (coproduction of value, front stage versus back stage, and so on) and seven generic processes expressed in the service value chain framework, and four phases of the work system life cycle model. In other words, it identified at least 25 areas of potential service innovation that apply across a vast range of service situations. 
Challenge for other service innovation models. The three frameworks presented in this paper are applicable to all service innovations in organizations. The systemoriented approach to service innovation poses several implicit challenges for other frameworks or models related to service innovation. The first challenge involves breadth: Do the alternative frameworks or models have the same breadth, or are they relevant to specific types of service situations, such as hotels, hospitals, law firms, software as a service, or IT consulting? The second challenge involves utility: This paper's three frameworks lead directly to 25 directions for possible service innovation. When comparing the view of service innovation presented here with any other view, one would immediately think about which types of innovation opportunities or possibilities are implied by alternative models, how broad are the relevant service areas, and which areas of service simply aren't covered.

What is next? The ultimate test of the ideas presented here is whether they help SSI practitioners and researchers understand and analyze real-world situations, and whether they help instructors teach about service and service innovation. Steps in that direction include

- Developing detailed comparisons between the three frameworks and other frameworks that might be used to understand and guide service innovation efforts

- Using the three frameworks to summarize existing accounts of service innovation, identify omissions, and draw lessons for the future

- Developing guidelines for using the three frameworks during service innovation projects

- Testing those guidelines through action research and other research methods

- Developing educational and training material that help people use the three frameworks in delivering and managing services and in creating service innovations

Each of these steps is a substantial project that could generate valuable results.

\section{References}

Alter, S. 2003. “18 Reasons Why IT-Reliant Work Systems Should Replace the IT Artifact as the Core Subject Matter of the IS Field," Communications of the Association for Information Systems (12:23), pp. 365-394.

Alter, S. 2006. The Work System Method: Connecting People, Processes, and IT for Business Results, Larkspur, CA: Work System Press.

Alter, S. 2007. "Service Responsibility Tables: A New Tool for Analyzing and Designing Systems," in Proceedings of the $15^{\text {th }}$ Americas Conference on Information Systems, Keystone, CO, August 9-12.

Alter, S. 2008. "Service System Fundamentals: Work System, Value Chain, and Life Cycle," IBM Systems Journal (47:1), pp. 71-85 ( http://www.research.ibm.com/journal/sj/471/ alter.html).

Brown, A. W., Delbaere, M., Eeles, P., Johnston, S., and Weaver, R. 2005. "Realizing ServiceOriented Solutions with the IBM Rational Software Development Platform," IBM Systems Journal (44:4), pp. $727-752$ (http://www.research.ibm.com/journal/sj/444/brown.pdf).

Carlzon, J. 1989. Moments of Truth, New York: Harper Collins.

Chesbrough, H., and Spohrer, J. 2006. "A Research Manifesto for Services Science," Communications of the ACM (49:7), pp. 35-40. 
Christensen, C. M., Cook, S., and Hall, 5. 2005. "Marketing Malpractice: The Cause of the Cure," Harvard Business Review (83:12), pp. 74-83.

Fitzsimmons, J. A., and Fitzsimmons, M. J. 2006. Service Management: Operations, Strategy, and Information Technology ( $5^{\text {th }}$ ed.), Boston: Irwin/McGraw-Hill.

IfM and IBM. 2007. Succeeding through Service Innovation: A Discussion Paper, University of Cambridge Institute for Manufacturing (IfM) and International Business Machines Corporation (IBM), October (http://www.ifm.eng.cam.ac.uk/ssme/documents/ssme_ discussion_final.pdf).

Hill, T. P. 1977. "On Goods and Services," The Review of Income and Wealth (23:4), pp. 315-338.

Kotler, P., and Keller, K. 2006. Marketing Management (12 ${ }^{\text {th }}$ ed.), Upper Saddle River, NJ: Prentice Hall.

Krogh, E., El Sawy, O. A., and Gray , P. 2005. "Managing Online in Perpetual Perfect Storms: Insights from IndyMac Bank," MIS Quarterly Executive (4:4), pp. 425-442.

McGovern, G., and Moon, Y. 2007. "Companies and the Customers Who Hate Them," Harvard Business Review (85:6), June, pp. 78-84.

Rai, A., and Sambamurthy, V. 2006. "Editorial Notes: The Growth of Interest in Services Management: Opportunities for Information System Scholars," Information Systems Research (17:4), December, pp. 327-331.

Sampson, S. E., and Froehle, C. M. 2006. "Foundations and Implications of a Proposed Unified Services Theory," Production and Operations Management (15:2), pp. 329-343.

Schumpeter, J. A. 1934. The Theory of Economic Development, Boston: Harvard University Press.

Spohrer, J., Maglio, P. P., Bailey, J., and Gruhl, D. 2007. "Steps Toward a Science of Service Systems," IEEE Computer (40:1), pp. 71-77.

Spohrer, J., Vargo, S. L., Caswell, N., and Maglio, P. P. 2008. "The Service System Is the Basic Abstraction of Service Science," in Proceedings of the $41^{\text {st }}$ Hawaii International Conference on Systems Sciences, Los Alamitos, CA: IEEE Computer Society Press.

Stabell, C. B., and Fjeldstad, O D. 1998. "Configuring Value for Competitive Advantage: On Chains, Shops, and Networks," Strategic Management Journal (19), pp. 413-437.

Teboul, J. 2006. Service Is Front Stage: Positioning Services for Value Advantage, New York: Palgrave Macmillan.

Van Halen, C., Vezzoli, C., and Wimmer, R. 2005. Methodology for Product Service System Innovation: How to Implement Clean, Clever, and Competitive Strategies in European Industries, Assen, Netherlands: Royal Van Gorcum.

Vargo, S. L., and Lusch, R. F. 2004. "Evolving to a New Dominant Logic for Marketing," Journal of Marketing (68), pp. 1-17.

Vargo, S. L., and Lusch, R. F. 2006. "Service-Dominant Logic: What It Is, What It Is Not, What It Might Be," in The Service-Dominant Logic of Marketing: Dialog, Debate, and Directions, R.F. Lusch and S. L. Vargo (eds.), Armonk, NY: M. E. Sharpe, pp. 43-56.

Wikipedia. 2008. "Innovation" (http://en.wikipedia.org/wiki/Innovation, viewed on March 17, 2008).

Wood, J. B. 2007. "Major Service Challenges Facing Technology Companies in 2007," presentation at the $16^{\text {th }}$ Annual Frontiers of Service Conference, San Francisco, CA, October 4-7.

\section{About the Author}

Steven Alter is a professor of Information Systems at the University of San Francisco. He received a Ph.D. from MIT, taught at the University of Southern California, and was vice president 
of the manufacturing software firm Consilium before joining USF. His research for over a decade has concerned developing systems analysis concepts and methods that can be used by typical business professionals and can support communication with IT professionals. His latest book, The Work System Method: Connecting People, Processes, and IT for Business Results, is a distillation and significant extension of ideas in four editions $(1992,1996,1999,2002)$ of his information system textbook. His articles have been published in Harvard Business Review, Sloan Management Review, MIS Quarterly, IBM Systems Journal, Communications of the Association for Information Systems, and other journals and conference proceedings. Steve can be reached at stevenalter@comcast.net. 